\title{
Is surgery for multiple lung metastases reasonable? A total of 328 consecutive patients with multiple-laser metastasectomies with a new 1318-nm Nd:YAG laser
}

Axel Rolle, MD, PhD, ${ }^{a}$ Arpad Pereszlenyi, MD, PhD, ${ }^{a}$ Rainer Koch, MD, PhD, ${ }^{b}$ Mathias Richard, MD, ${ }^{a}$ and Barbara Baier ${ }^{\mathrm{a}}$

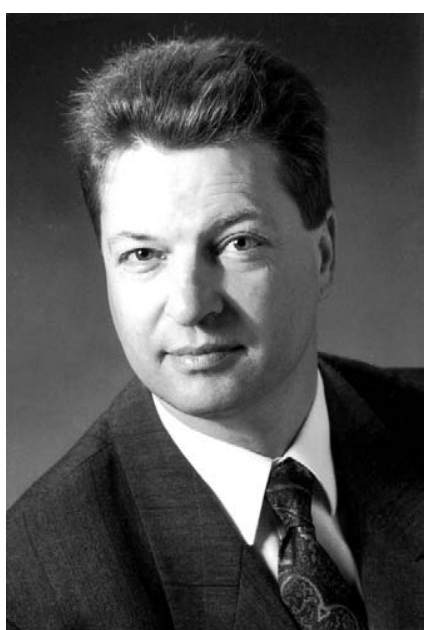

Dr Rolle

From the Department of Thoracic and Vascular Surgery, ${ }^{\text {a }}$ Coswig Specialised Hospital, Center for Pneumology and Thoracic Surgery, University Medical Center, Coswig/ Dresden, Germany, and the Department of Informatics, ${ }^{\mathrm{b}}$ Carl Gustav Carus University, Dresden, Germany.

Read at the Eighty-fifth Annual Meeting of The American Association for Thoracic Surgery, San Francisco, Calif, April 10-13, 2005.

Received for publication June 20, 2005; revisions received Nov 17, 2005; accepted for publication Nov 28, 2005.

Address for reprints: Axel Rolle, MD, $\mathrm{PhD}$, Department of Thoracic and Vascular Surgery, Coswig Specialised Hospital, Center for Pneumology and Thoracic Surgery, Affiliated to the Carl Gustav Carus University Dresden, Neucoswiger Straße 21, D01640 Coswig/Dresden, Germany (E-mail: dr.rolle@fachkrankenhaus-coswig.de).

J Thorac Cardiovasc Surg 2006;131:1236-42 $0022-5223 / \$ 32.00$

Copyright (C) 2006 by The American Association for Thoracic Surgery

doi:10.1016/j.jtcvs.2005.11.053
Objective: Our objective was to define the role of a new 1318-nm Nd:YAG laser for lobe- and parenchyma-saving resection of multiple lung metastases.

Patients and Methods: From January 1996 to December 2003, a total of 3267 nodules (10/patient) were removed from 328 patients (164 men/164 women, mean age 61 years). Criteria for eligibility were expanded to any primary tumors with no upper limit of metastases given. All parenchymal resections were performed with a new 1318-nm Nd:YAG laser whose effect on lung tissue differs significantly from that of the 1064-nm wavelength owing to a 10-fold higher absorption in water and one-third extinction in blood. In 93\%, precision laser resection was achieved. The lobectomy rate was only $7 \%$.

Results: Pathologic examination revealed 2546 metastases (8/patient) and lymph node disease in 19\%. Complete resections (R0) were achieved in $93 \%$ of 177 patients undergoing unilateral procedures with a mean of 3 metastases (range $1 \%-29 \%$ ) and $75 \%$ of 151 patients having bilateral operations with a mean of 13 metastases (range 2-124). The 5-year survival after R0 was 55\% for solitary nodules, $41 \%$ for all patients, $28 \%$ for 10 metastases, and $26 \%$ for 20 or more metastases resected. Outcome was significantly poorer after incomplete resection (7\%). No 30-day mortality was observed. Major postoperative complications included prolonged air leaks $(\mathrm{n}=2)$, intrapleural bleeding $(\mathrm{n}=2)$, and late pneumothorax $(n=2)$; all were treated successfully with a chest tube.

Conclusion: This new 1318-nm Nd:YAG laser facilitates complete resection of multiple bilateral centrally located metastases and thus is lobe sparing. Resection of 20 or more metastases is reasonable because long-term survival was significantly better than that observed with incomplete resection.

$\mathrm{T}$ he therapeutic value of pulmonary metastasectomy has been gradually accepted and nowadays this operation is routinely performed in many departments, but only in carefully selected cases and commonly for 5 or fewer metastases. ${ }^{1-4}$

So that a more extensive database would be available for areas of major controversy (the selection of patients, the maximum number of resectable metastases, the role of bilateral surgery, the significance of secondary lymph node metastases, and surgical techniques), the International Registry of Lung Metastases (IRLM) was launched in 1990 and the results of 5206 cases were reported in $1997 .{ }^{4}$ The study confirmed that metastasectomy in general is a potentially curative treatment, even for patients having redo surgery and for those with higher numbers of metastases. However, despite these encouraging results, a classification of prognostic groups was offered, leading again to more restricted selection of patients.

With the results of our institution's study we want to report on a new 1318-nm wavelength Nd:YAG laser system that we have developed. This laser facilitates 


\section{Abbreviations and Acronyms \\ IRM = International Registry of Lung Metastases}

lobe-sparing precision resection of a large number of metastases and thus improves complete resection, which is the most important prognostic factor after surgery. As a result of systematic lymph node dissection in all patients, we can offer additional results for metastasectomy with concomitant lymph node disease in patients with epithelial primary tumors in a clinical setting previously considered to have a poor prognosis. Furthermore, we want to encourage progressive expansion of eligibility of patients for salvage surgery and strengthen the role of pulmonary metastasectomy in the interdisciplinary treatment of metastatic disease.

\section{Patients and Method}

\section{Scientific Background}

After studying lung tissue determinants in $1986,{ }^{5,6}$ we recognized that lung parenchyma with $80 \%$ water content, very low tissue density (one fifth of liver), and high shrinking capacity owing to alveolar air content demonstrated qualities very well suited to photothermal laser resection. The challenge to gain benefit for all types of parenchymal lung resections was to find and add the best laser parameters. Our first experiments showed that only an $\mathrm{Nd}$ : YAG laser can offer the intended combination effect of cutting and coagulation. In contrast to the 1064-nm standard wavelength exclusively offered by the industry at that time, we suspected the second wavelength of 1318-nm to be superior owing to its 10 times higher absorption in water and still sufficient laser light scattering. ${ }^{7,8}$ In fact, this wavelength provided significantly better cutting and coagulation qualities and caused strong tissue shrinking as a welcome side-effect reinforcing mechanical stability of the periphery of the resection area and thus sealing off air leaks deep in the center of lobes. More details of the biophysical background and development of this laser device were previously published by the first author (A.R.). ${ }^{5,6,9,10}$ Parenchymal laser resection technique can actually be seen in video sequences via the Internet. ${ }^{11}$

\section{Indications for Laser Metastasectomy}

Criteria for progressively expanded eligibility for laser metastasectomy are indicated in Table 1, whereas exclusion criteria are the same as for thoracic surgery generally. After evaluation for complete resection of the original tumor and other extrathoracic metastases, we accepted any primary malignancy with single or multiple, synchronous or bilateral lung metastases. No limit to the number of metastases was given, but assessment of functional and technical resectability by a thoracic surgeon experienced with this special laser technique was mandatory as well as routine examination with a flexible bronchoscope. Furthermore, patients with suspected N2 lymph node disease in their preoperative computed tomographic scans had transtracheal, transbifurcal, or transesophageal biopsy of lymph nodes with combined rigid and flexible bronchoscopy or endosonography. Only patients with unilateral N2 disease and suspected resectability were included. In case of subcarinal lymph nodes, only solitary nodules were accepted.

TABLE 1. Criteria for progressively expanded eligibility for laser metastasectomy Criteria of eligibility for
metastasectomy

- Any primary malignancy

- Primary completely resected

- No extrathoracic metastases incompletely resected

- Unilateral and bilateral metastases

- No limit to number (the limit is functional and technical resectability)

- Lymph node involvement up to $\mathrm{N} 2$ unilateral

- Previous chemotherapy

$F E V_{1}$, Forced expiratory volume in 1 second.

All sublobar laser resections and combined lobectomies (lobectomy rate 7\%, bronchoangioplastic procedures included) were performed via an anteroaxillary muscle- sparing approach (staged 3 to 4 weeks if bilateral) beginning with the side considered to be the more difficult. Parenchymal resections were exclusively performed by 1318-nm Nd:YAG laser. No bioadhesives or stapling devices were used because even for small peripheral nodules the parenchyma-saving effect is impressive. The loss of tissue after precision laser resection was measured to be up to 7-fold smaller than with stapler resections. During surgery every palpable nodule down to $1 \mathrm{~mm}$ in size was resected by "precision" laser resection with a 3-mm tumor margin and sent for pathologic examination. One important strength of this laser technique is the easy optical control of the tumor margin during bloodless parenchymal resection and the fact that an additional laser necrosis zone of minimal $0.5-\mathrm{cm}$ diameter remains in situ with the patient. ${ }^{5,9,11}$ Thus, frozen section examinations were necessary only in selected cases when infiltration of great bronchovascular structures was suspected. Resection margins of any nodule removed were definitely analyzed by our pathologist, who describes the amount of normal lung tissue around the metastasis resected. In the rare case of a final pathology report indicating an incomplete circumferential ring of normal lung tissue around the removed metastasis (ie, in case of R1 resection), the follow-up is continued by patient observation, also owing to the previously mentioned fact of the additional laser necrosis zone of $0.5-\mathrm{cm}$ size of the in situ site.

Systematic lymph node sampling according to Naruke's classification $^{11 \mathrm{a}}$ was mandatory; in cases of N2 disease, mediastinal dissection was performed. Resection was considered complete if no macroscopic chest disease remained in situ and resection margins were negative for tumor. In the presence of lymph nodes, they had to be resected with no gross or microscopic capsular escape. 
TABLE 2. Distribution of primary cancers in our series

\begin{tabular}{lc}
\hline Site & No. of patients $(\%)$ \\
\hline Kidney & $112(34 \%)$ \\
Colorectal & $91(28 \%)$ \\
Breast & $35(11 \%)$ \\
Sarcoma & $15(4 \%)$ \\
Gynecologic & $13(4 \%)$ \\
Bronchogenic & $12(4 \%)$ \\
Melanoma & $11(3 \%)$ \\
Head/neck & $12(4 \%)$ \\
Other & $27(8 \%)$ \\
Total & $328(100 \%)$ \\
\hline
\end{tabular}

\section{Demographics and Procedures}

From January 1996 to December 2003, a total of 328 patients, 164 men and 164 women with a mean age of 61 years (range 20-80 years) were eligible for enrollment in this single center and institutional review boarded retrospective study. They underwent 484 thoracotomies. A mean hospital stay of 10 days was observed, comparable with that of German thoracic departments. Complete follow-up (mean 31 months, range 1-198 months, median 22.5 months) was achieved for all patients. In only 23 patients $(7 \%)$ were we unable to clarify whether the recurrence of metastases was pulmonary or extrathoracic (or both) and thus the differentiation of recurrence remained unclear. A total of 3267 nodules (10/patient) were removed. Despite the $40 \%$ central location of metastases, in $93 \%$ precision sublobar laser resection was achieved. In only $7 \%$ a lobectomy or a bronchoangioplastic procedure was necessary. Pathologic examination revealed 2546 metastases (8/ patient), $20 \%$ benign lesions, and simultaneous lymph node metastases in $19 \%$. Under these conditions, complete resection was achieved in $93 \%$ of 177 patients undergoing unilateral procedures with a mean of 3 metastases resected per patient (range 1-29) and $75 \%$ of 151 patients having bilateral operations with a mean of 13 metastases removed per patient (range 2-124). Causes of incomplete resections in 50 patients $(15 \%)$ were unexpected intraoperative miliary spread of metastases, unresectable lymph node disease, or pleural dissemination of the tumor excluding the patients from further surgery. For 22 patients, incomplete resection was the result after the first surgery and the operation for the second side was not performed. Ninety-one percent of the primary tumors were epithelial tumors (carcinoma), with kidney cancer as the leading primary tumor $(\mathrm{n}=112)$ followed by colorectal $(\mathrm{n}=91)$ and breast cancer $(\mathrm{n}=35)$. Sarcoma and melanoma were found in only $6 \%$ and $3 \%$, respectively. Table 2 shows the distribution of primary tumors.

\section{Results}

For multiple sublobar laser resections of lung metastases a very low perioperative and postoperative morbidity was observed. Even in combination with lobectomies and bronchoplastic procedures (7\%), no 30-day mortality occurred and no patient died in the hospital after metastasectomy. Major postoperative complications included 2 cases of prolonged air leak ( $>7$ days in patients with 40 and

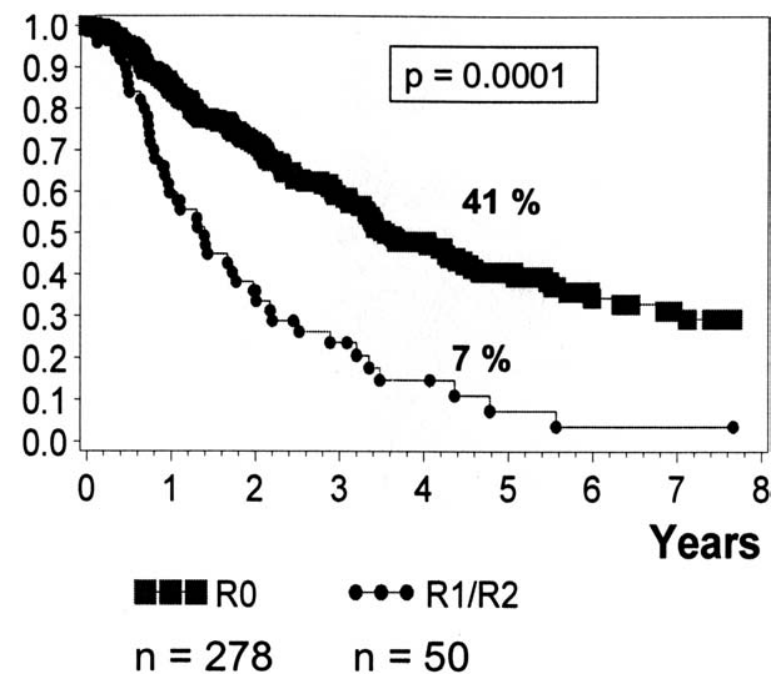

Figure 1. Overall survival after complete (RO) resection versus significantly poorer incomplete $(R 1 / R 2)$ resection $(P=.0001)$. Squares $=\mathrm{R} 0$; bullets $=\mathrm{R} 1 / \mathrm{R} 2$.

60 metastastatic lesions resected, respectively), 2 cases of intrapleural bleeding that required decortication at the time of metastasectomy owing to previous surgery, and 2 cases of late pneumothorax (4 and 6 weeks after discharge) in young patients during sports activities. All complications were successfully treated by chest tube; there was no need for reoperation. No further delayed air leaks or pneumothoraces were observed with a maximal follow-up time of 7 years.

Overall survival for all cell types was $81 \%, 53 \%$, and $35 \%$ for 1,3 and 5 years, respectively. The most important prognostic factor for survival was completeness of resection (Figure 1). The 1-, 3-, and 5-year survivals for patients having complete resection, with a mean of 8 metastases removed per patient, were $85 \%, 59 \%$, and $41 \%$ versus $60 \%$, $23 \%$, and $7 \%$ for those having incomplete resection $(P<$ .0001). No statistical significance $(P=.2)$ was found when complete resections including regional lymph nodes (R0 $\mathrm{N} 1 / 2$ ) were compared with complete resections without lymph node disease (R0 N0) (Figure 2).

Compared with unilateral procedures (Figure 3), a significant higher number of metastases were resected with staged bilateral operations (mean 3 versus 13 metastases) associated with a decrease of complete resection rate $(93 \%$ versus $75 \%$ ), but 5 -year survivals of $36 \%$ showed no significantly poorer outcome for patients after completely resected bilateral metastases.

There is a widespread acceptance that the number of metastases is another important prognostic factor implicating an upper limit. ${ }^{2,12,13}$ Figure 4 and Table 3 demonstrate survival of patients after complete resection of metastases in 


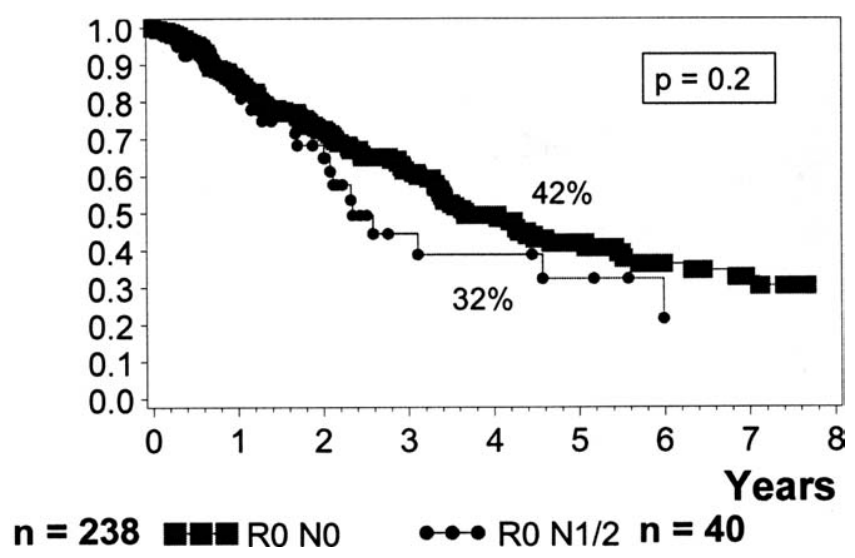

Figure 2. Overall survival after complete resection of metastases with ( $R O N 1 / 2$ ) or without ( $R O$ NO) lymph node disease (no significance $P=$.2). Squares $=$ RO N0; bullets $=$ RO N1/N2.

different groups from 1 up to 20 and more in comparison with the results published by the IRLM. ${ }^{4}$ In contrast to 18 centers of this Registry describing significance in survival even between 1 and 2 metastases, our statistical analysis found no significance between solitary and multiple metastases up to a total of $9(P=.52)$. Just with the group of 10 to 19 metastases, a statistically significant difference compared with survival with solitary metastases was found $(P=$ .002). But complete resection of 20 or more metastases still demonstrates significantly better outcome than the poor $7 \%$ 5-year survival for incomplete resection. Solitary metastasis was found in only $28 \%$ in our series. In contrast, nearly half of our patients had 4 or more metastases, $21 \%$ had 10 or

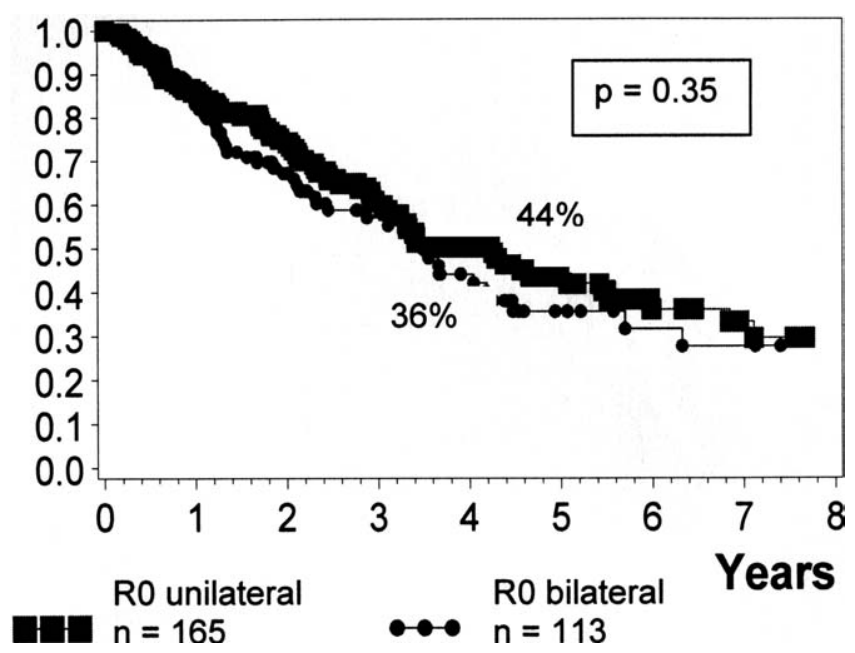

Figure 3. Overall survival after complete resections. Unilateral versus staged bilateral surgery for lung metastases (no significance $\boldsymbol{P}=.35$ ). Squares $=\mathrm{RO}$ unilateral; bullets $=\mathrm{RO}$ bilateral.

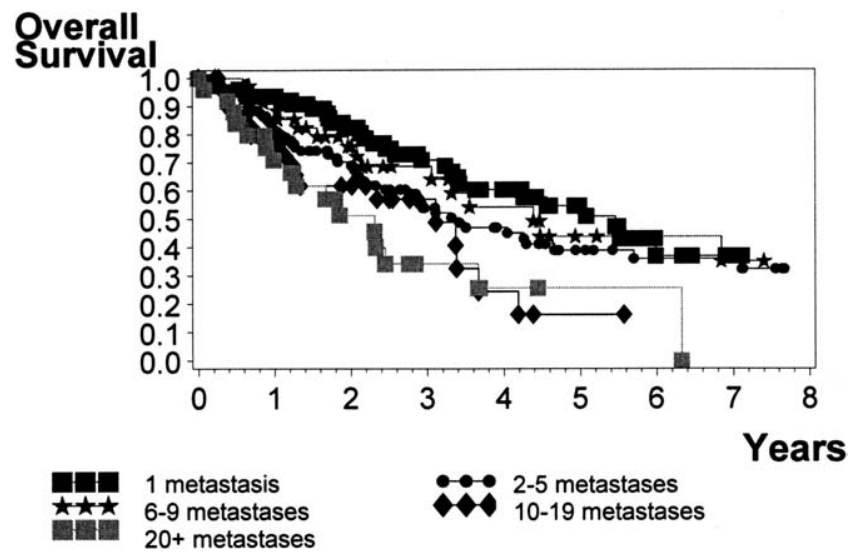

Figure 4. Influence of the number of completely resected metastases on survival. Dark squares $=1$ metastasis $(\mathrm{n}=78$ ); bullets $=2$ to 5 metastases $(n=106)$; stars $=6$ to 9 metastases $(n=37)$; diamonds $=10$ to 19 metastases $(n=32)$; light squares $=20$ or more metastases $(\mathbf{n}=\mathbf{2 5})$.

more, and $9 \%$ of our patients had 20 or more metastases followed by a 5-year survival of $26 \%$.

Follow-up for all patients was complete except for $7 \%$ in whom we could not define the site of recurrence. For the rest of the patients, recurrence rate after complete resection was $60 \%$ with a mean of 12 months or a median of 9 months to recurrence, respectively. Twenty-nine percent of these patients had extrathoracic, $31 \%$ pulmonary and extrathoracic, and $40 \%$ had isolated recurrence to the lung. Thirty-two percent of patients with pulmonary recurrence and $10 \%$ of those with extrathoracic and pulmonary recurrence had redo surgery after complete resection of their extrathoracic metastases. With respect to the leading primary tumors, a nearly constant percentage of patients (35\% renal cell carcinoma, $36 \%$ colorectal, $32 \%$ breast cancer) remained without recurrence and had a disease-free course. Distribution of unilateral versus bilateral thoracotomies among these

TABLE 3. Five-year survival for different number of completely resected metastases in our series $(R O n=278$, compared with IRLM ${ }^{4}$ )

\begin{tabular}{lrcrrrr}
\hline \multirow{2}{*}{$\begin{array}{l}\text { No. of } \\
\text { metastases }\end{array}$} & \multicolumn{2}{c}{ IRLM } & & \multicolumn{2}{c}{ Coswig } & \\
\cline { 2 - 3 } & 5 & 5-y survival & & $\mathbf{n}$ & $\%$ & 5-y survival \\
\hline 1 & 47 & 43 & & 78 & 28 & 55 \\
$2-3$ & 27 & 34 & & 64 & 23 & 33 \\
$4+$ & 26 & 27 & & 136 & 49 & 36 \\
Total & 100 & & & 278 & 100 & \\
$10+$ & 9 & 26 & & 57 & 21 & 28 \\
$20+$ & 3 & - & & 25 & 9 & 26 \\
\hline
\end{tabular}

The International Registry of Lung Metastases (IRLM) number of patients was not available. 
disease-free patients was comparable, and the highest number of resected metastases was 20 for renal cell carcinoma, 9 for colorectal, and 40 for breast cancer.

\section{Discussion}

At the end of the 1980s and the beginning of the 1990s, some centers tried to introduce the Nd:YAG laser for parenchymal resection, but the 1064-nm wavelength available at that time could not provide sufficient cutting and coagulation qualities to handle extended resection to the center of a lobe. ${ }^{14-16}$ Thus only a few patients were enrolled in studies and further reports on laser surgery to the lung dried up. We initiated a new start in this by identifying the 1318-nm wavelength to provide simultaneously the 3 qualities (cut, coagulate, seal) needed for deep parenchymal lung resection due to a 10 -fold higher absorption in water and only onethird extinction in blood. A laser device delivering sufficient power output to generate this 1318 -nm wave length was developed in our institution. ${ }^{5,6,10}$ Since 1996 the significant number of 328 patients with 484 thoracotomies performed were eligible for us to report on metastasectomy using this new laser technology. Owing to improvement of surgical technique, we aggressively expanded the criteria of eligibility to include any malignant primary tumor with unilateral resectable $\mathrm{N} 2$ disease and gave no definitive limit to the number of metastases, a radical approach not yet reported by other authors. Repeated palpation of the completely deflated lung and laser resection of any nodule identified by an experienced thoracic surgeon was mandatory to gain complete resection. Under these conditions, 3267 lesions (10/patient) were removed and pathologic assessment revealed 2546 metastases (8/patient). Our results are discussed with recent publications but with special respect to those published by the IRLM, representing 18 renowned centers of thoracic surgery and the greatest database of information available for metastasectomy. Despite the high number of metastases resected and the presence of $19 \%$ lymph node metastases, a similar rate of complete resection (85\% vs $88 \%$ ) was observed. Besides the controversy of selection of patients, the resection of multiple, large, hilar, and centrally located metastases is first of all a matter of surgical technique. When electrocautery, clamps, or staplers are used, the number of metastases that can be resected is limited and the lobectomy rate using these techniques is frequently reported as $20 \%$ to $25 \%,,^{1,3,4} 3$-fold higher than in our series. In a recently published study, Murthy and associates ${ }^{18}$ had calculated the probability of incomplete resection in relation to the number of metastases for the use of conventional technique. The likelihood of incomplete resection reached $80 \%$ when there were 6 metastases and approximately $100 \%$ when there were 8 nodules identified on preoperative chest computed tomography. Murthy and colleagues ${ }^{18}$ emphasized that the preoperative account of pulmonary nodules accurately reflected the number of nodules resected. These actual results are well suitable to discuss the advantages of this laser resection technique with a mean of 10 nodules and a maximum of 124 metastases completely resected in $85 \%$ of the patients in our series. We found the main cause of incomplete resections $(15 \%)$ to be inaccuracy of computed tomographic scans of candidates with preoperatively known high numbers of metastases. In these cases, intraoperative unexpected miliary spread of metastases or pleural dissemination of the tumor and unresectable lymph node disease were the reasons for incompleteness. In $93 \%$ versus $75 \%$ (IRLM), precision sublobar laser resections up to segmental resection were performed according to the size of the metastasis, with a maximum of $8 \mathrm{~cm}$. This high percentage of limited resections together with a significant reduction of lobectomy rate (7\% vs 22\%) indicates the parenchyma-saving effect of this laser technique.

Complete resection is the most important prognostic factor and thus functional and technical resectability should be the central criteria of eligibility. When complete resection is gained, a 5-year survival of $41 \%$ is observed, all cell types included, and no significantly poorer outcome was seen for associated lymph node disease and bilateral resections. In contrast to many other studies, our study found no significance for the outcome between patients with solitary and multiple (up to 9 ) metastases. ${ }^{1-4}$

Patients with a disease-free interval greater than 36 months showed significantly better survivals (55\%), but patients with a mean of 8 synchronous metastases $(<12$ months) who underwent complete resection still had 5-year survival of $34 \%$. In summary, we want to assert that the prognostic value of traditional factors (solitary, disease-free interval, number) is diminished if the technical ability to perform a complete resection can be improved. We found these arguments further confirmed with a 5-year survival of $36 \%$ for patients with 4 or more, $28 \%$ for 10 or more, and finally $26 \%$ for 20 or more metastases completely resected.

We conclude that this new 1318-nm laser system improves any kind of lung parenchymal resection, facilitates complete resection of multiple bilateral and centrally located metastases, and thus is lobe sparing. Owing to our results, we believe that these resections are reasonable and worthwhile. For the immediate future we expect to have a sufficient number of patients enrolled in our study to allow us to evaluate results according to cell type. And because a growing number of centers having taken over this technology, we should be able to start a prospective randomized trial analyzing the value of multimodality treatment in combination with a laser metastasectomy. 


\section{Limitations}

This study is limited by several factors: (1) comprises the clinical experience of a single institution and a new technology; (2) lack of differentiation according to the cell type; (3) lack of preoperative positive emission tomographycomputed tomography scan screening for extrathoracic spread of metastases; (4) $91 \%$ epithelial primary tumors estimated to have poorer prognosis; (5) selection of patients, the majority initially being classified as having unresectable disease. ${ }^{17}$

\section{References}

1. Mountain CF, McMurtrey MJ, Hermes KE. Surgery for pulmonary metastasis: a 20-year experience. Ann Thorac Surg. 1984;38:323-30.

2. Venn GE, Sarin S, Goldstraw P. Survival following pulmonary metastasectomy. Eur J Cardiothorac Surg. 1989;3:105-9.

3. Thomford NR, Woolner LB, Clagett OT. The surgical treatment of metastatic tumors in the lungs. J Thorac Cardiovasc Surg. 1965;49: 357-63.

4. Pastorino U, Buyse M, Friedel G, Ginsberg RJ, Girard P, Goldstraw P, et al. Long-term results of lung metastasectomy: prognostic analyses based on 5206 cases. The International Registry of Lung Metastases. J Thorac Cardiovasc Surg. 1997;113:37-49.

5. Rolle A, Unsöld E, Ruprecht L, Permanetter W, Frank F. Morphologic aspects of Nd:YAG laser application (wavelengths $1064 \mathrm{~nm}$ and 1318 $\mathrm{nm}$ ) on lung tissue. Laser Med Surg. 1988;4:10-4.

6. Rolle A, Thetter O, Häussinger K, Hallfeldt KKJ, Schmölder A. Einsatz des Neodym YAG Lasers in der Thoraxchirurgie. Herz Gefäss Thorax Chir. 1989;3:85-91.

7. Bayly IG, Kartha VB, Stevens WH. The absorption spectra of liquid phase $\mathrm{H}_{2} \mathrm{O}, \mathrm{HDO}$, and $\mathrm{D}_{2} \mathrm{O}$ from 0.7 micron to 10 micron. Infrared Physics. 1963;3:211-23.

8. Bramson M. Infrared radiation: a handbook for applications. New York: Plenum Press; 1968.

9. Rolle A. Laser applications in lung parenchyma surgery. Med Laser Appl. 2003;18:271-80.

10. Rolle A, Koch R, Alpard SK, Zwischenberger JB. Lobe-sparing resection of multiple pulmonary metastases with a new $1318 \mathrm{~nm} \mathrm{Nd}$ : YAG laser-first 100 patients. Ann Thorac Surg. 2002;74:865-9.

11. Rolle A, Pereszlenyi A. Laser resection of lung metastasis. Multimedia Manual of Cardiothoracic Surgery. 2005; doi.10.1510/mmcts. 2004.000570. http://mmcts.ctsnetjournals.org/cgi/collection/surgery_ metastatic_lung.

11a.Naruke T, Suemasu K, Ishikawa S. Lymph node mapping and curability at various levels of metastasis in resected lung cancer. J Thorac Cardiovasc Surg. 1978;76:832.

12. McCormack P. Surgical treatment of pulmonary metastases: Memorial Hospital experience. In: Weiss L, Gilbert HA, editors. Pulmonary metastasis. Boston: GK Hall; 1978.

13. Girard P, Baldeyrou P, Le Chevalier T, Le Cesne A, Brigandi A, Grunenwald D. Surgery for pulmonary metastases. Who are the 10year survivors? Cancer. 1994;74:2791-7.

14. Kodama K, Doi O, Higashiyama M, Massayuki T, Iwanaga T. Usefulness of resection with the neodymium:yttrium-aluminium-garnet laser with median sternotomy. J Thorac Cardiovasc Surg. 1991;101: 901-8.

15. LoCicero J, Hartz RS, Frederiksen JW, Michaelis LL. New applications of the laser in pulmonary surgery. Hemostasis and sealing of air leaks. Ann Thorac Surg. 1985;40:546-50.

16. Moghissi K. Local excision of pulmonary nodular (coin) lesions with noncontact yttrium-aluminium-garnet laser. J Thorac Cardiovasc Surg. 1989;97:147-51.

17. Doehn C, Jocham D. Immunotherapy of renal cell carcinoma: results from current phase-III-trials. Aktuel Urol. 2004;35:121-9.

18. Murthy SC, Kim K, Rice TW, Rajeswaran J, Bukowski R, DeCamp $\mathrm{MM}$, et al. Can we predict long-term survival after pulmonary metastasectomy for renal carcinoma? Ann Thorac Surg. 2005;79:996-1003.

\section{Discussion}

Dr David R. Jones (Charlottesville, $\mathrm{Va}$ ). I wish to congratulate Dr Rolle and his colleagues from Dresden on a remarkable series with excellent clinical results of 328 patients with more than 2200 resected metastases. It appears as though this technique affords the surgeon the ability to actually preserve lung parenchyma and additionally potentially increases the number of patients who may be eligible for metastasectomy, even those who have a significant number of bilateral metastases. I have several questions for $\mathrm{Dr}$ Rolle, which I will ask one at a time.

I was surprised and impressed that the rate of lobectomy was 3 -fold less than what was seen in the international registry. Do you find that your need to perform a lobectomy is now based more on the central location of the lesion or is it based more on the fact that there are so many lesions in a given lobe that you in fact have to perform a lobectomy?

Dr Rolle. The lobectomy rate could be lowered as much as $7 \%$ in this series compared with other series, in which the lobectomy rate is $20 \%$ to $25 \%$. The cases in which we have to do a lobectomy involve very great metastases located with the central vessels. These are the only cases in which we have to perform lobectomy or bronchoplastic surgery.

Dr Jones. Part of the premise of using the 1318-nm laser is that you are actually preserving lung parenchyma. Do you have any pulmonary function data on these patients before and then after metastasectomy? Were you able to make a retrospective comparison between an older group of patients who had staples used for their metastasectomy and your current, laser-treated group to see whether you actually are preserving lung parenchyma?

Dr Rolle. That is a very interesting question. We had measurements of all ventilatory parameters preoperatively and postoperatively. I don't have the statistical analysis yet, but we will do it. We could see that after 3 months and 6 months, most of the patients who have had resection of more than 30 or 40 metastases returned to a lung function between $80 \%$ and $90 \%$ of the preoperative value.

Dr Jones. Finally, how do you handle the more central aspect of this "sculpted" resection, if you will, of the metastatic lesions as you begin to approach the larger vessels centrally in the segmental bronchi?

Dr Rolle. If we have to operate very close to the central vessels, we secure it by vessel-loop. However, with some experience, we can approach very close even to the hilar structures. For example, if we have a resection with metastases of a diameter of 6 or $7 \mathrm{~cm}$, then we come to the segmental level and we finally resign ourselves to suturing the segmented bronchus and segmented artery. This is necessary. But the advantage is that one can oncologically safely go around the parenchymal tissue and come up to this level within the lobe.

Dr Joseph Zwischenberger (Galveston, Tex). When I first heard of Dr Rolle's work on the new laser 4 years ago in Germany, I said to myself, this is important, if true. Since that time I have evaluated this technology in my own laboratory, Dr Tom Daniels presented work at this meeting validating this technology, and now Dr Rolle is presenting 5-year follow-up on metastasectomy. What I can say is that this work is important and true. What I ask Dr Rolle is, how do you plan on allowing distribution of this new technology? 
Dr Rolle. We have some progress in Europe. In the meantime, more than 35 centers have taken over this technology in Germany and Austria and Italy and so on. The next step for this country is approval by the Food and Drug Administration. I hope that the company will come over with this in the near future.

Dr Zwischenberger. Excellent work.

Dr Adelheid End (Vienna, Austria). Do you perform mediastinal lymphadenectomy in all patients and how does it influence your strategy of adjuvant therapy?
Dr Rolle. We did systematic lymphadenectomy. I think all these metastasectomies should go through the same techniques then with bronchocarcinoma. We did systematic lymph node resection in every patient. I will give you the numbers: $14 \%$ of those having complete resections had lymph node disease and 85\%, N2 disease. We were surprised that the results were very good with complete resections. So we extended the indication and included patients with unilateral N2 disease, not with bilateral disease. They are not operated on.

Access to The Journal of Thoracic and Cardiovascular Surgery Online is reserved for print subscribers!

Full-text access to The Journal of Thoracic and Cardiovascular Surgery Online is available for all print subscribers. To activate your individual online subscription, please visit The Journal of Thoracic and Cardiovascular Surgery Online, point your browser to http://www.mosby.com/itcvs, follow the prompts to activate your online access, and follow the instructions. To activate your account, you will need your subscriber account number, which you can find on your mailing label (note: the number of digits in your subscriber account number varies from 6 to 10). See the example below in which the subscriber account number has been circled:

\section{Sample mailing label}

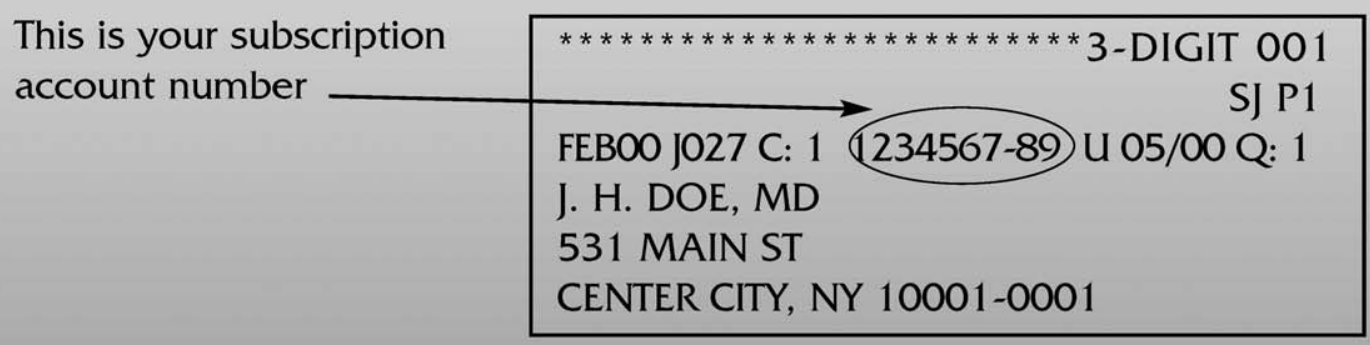

Personal subscriptions to The Journal of Thoracic and Cardiovascular Surgery Online are for individual use only and may not be transferred. Use of The Journal of Thoracic and Cardiovascular Surgery Online is subject to agreement to the terms and conditions as indicated online. 